\title{
Positioning business in uncertain conditions by weighting a competitive profile matrix using the fuzzy DEMATEL
}

\author{
Mohammad-Ali Faezi-Rad $^{\mathrm{a}^{*}}$ and Mohammad-Ali Khatami-Firoozabadi ${ }^{\mathrm{b}}$
}

${ }^{a}$ M.Sc. Student, Department of Industrial Management, Allameh Tabataba'i University, Tehran, Iran ${ }^{b}$ Associate Professor, Department of Industrial Management, Allameh Tabataba'i University, Tehran, Iran

\begin{tabular}{|c|c|}
\hline CHRON I C LE & AB S T R A C T \\
\hline $\begin{array}{l}\text { Article history: } \\
\text { Received January 14, } 2014 \\
\text { Accepted 10 June 2014 } \\
\text { Available online } \\
\text { June } 142014 \\
\text { Keywords: } \\
\text { Competitive Profile Matrix } \\
\text { Fuzzy DEMATEL } \\
\text { Strategic Management } \\
\text { Marketing }\end{array}$ & $\begin{array}{l}\text { In competitive markets, various businesses compete with other competitors for preservation and } \\
\text { development of their positions. This effort and competition can be demonstrated under various } \\
\text { criteria (component), which represent the position of company in business environment. There } \\
\text { are different tools to demonstrate accurate position of company or firm in a specific (target) } \\
\text { market and mentioned tools have been developed in strategic management and marketing. One } \\
\text { of these quantitative tools is Competitive Profile Matrix (CPM), which represents the position } \\
\text { of company compared with other competitors. CPM is based on scoring various criteria } \\
\text { (components) in target market of the company. The study proposes weighting in CPM matrix } \\
\text { based on the implementation of Fuzzy DEMATEL technique. The proposed model considers } \\
\text { uncertainty of weighting using fuzzy logic and the implementation of the proposed model is } \\
\text { demonstrated using a simple example. }\end{array}$ \\
\hline
\end{tabular}

\section{Introduction}

In the current era, use of strategic management for directing business is common and natural. The directions generally require various qualitative and quantitative methods to optimize and to determine the goals and places. Hence, it can be said that strategic planning embraces different means and techniques. It is a powerful means of increasing efficiency and productivity of organizations (Huang, 2009). On the other hand, organizational competitiveness is achieved when the organization meets the variable needs of its clients better than its rivals do and on a constant basis. In the market environment where economic, social and technological factors are active, it is difficult to maintain competitiveness at all stages (Ramachandran \& Voleti, 2004). In order to apply strategic planning in a competitive market to find a competitive place and save/enhance satisfactory attributes, strategies need to be formulated. This is a three-stage process, which results in a strategy formulated visual framework (David, 2011). In the formulation process, the Competitive Profile Matrix (CPM) is used *Corresponding author.

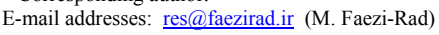


to determine the place of firms in competitive markets. This matrix makes it possible to compare the company of concern with its rivals and to find its place in a highly competitive and turbulent market (Zimmerer et al., 2008). Weighting market evaluation criteria is of great importance in obtaining the values for the CPM matrix. Hence, different means and methods developed for structuring factors and determining key components can be used to weight the matrix in more targeted and productive way. The DEMATEL method was therefore used in this study. It is one of the best methods for determination of basic components. The DEMATEL method was designed for structuring factors and determining their influence and effect (Thakkar et al., 2006). Definite weighting is used in CPM calculations, but in uncertain conditions, this method does not yield realistic results. Hence, fuzzy weighting is preferred to definite weighting in such conditions. By creating the CPM matrix and using the fuzzy weights provided by the fuzzy DEMATEL method it is possible evaluate businesses in the uncertain conditions of the competitive market with more certainty. This model was employed in this research and a final model was proposed by applying the fuzzy DEMATEL method to the CPM matrix.

\section{Literature Review}

\subsection{Competitive Profile Matrix (CPM)}

The Competitive Profile Matrix (CPM) is a means of helping companies with comparing themselves with their superior rivals and evaluating themselves against major factors of success in their industry (Zimmerer et al., 2008). This matrix identifies the chief rivals of a company and their strengths and weaknesses in relation to the strategic place of the company. Although many researchers classify this this matrix into the group of external environmental evaluation tools, some others consider them to be double purpose tools (Moradi, 2011). This matrix along with tools such as the external factors evaluation matrix (EFE) and the internal factors evaluation matrix (IFE) focus on the formulation of a strategic plan in the "Input Stage" (the first stage). As seen in Fig. 1, this stage is the first of three main stages in the process of formulating an organizational strategy. In this stage, input data and information are entered and examined for initial processing purposes and preparing for making decisions in the next stages (David, 2011).

\begin{tabular}{|c|c|c|c|c|}
\hline $\begin{array}{c}\text { External Factor } \\
\text { Evaluation (EFE) Matrix }\end{array}$ & & $\begin{array}{c}\text { Stage 1: The input stage } \\
\text { Competitive Profile Matrix (CPM) }\end{array}$ & & $\begin{array}{l}\text { Internal Factor Evaluation } \\
\text { (IFE) Matrix }\end{array}$ \\
\hline $\begin{array}{l}\text { Strengths-Weakness- } \\
\text { Opportunities-Threats } \\
\text { (SWOT) matrix }\end{array}$ & $\begin{array}{l}\text { Strategic Position and } \\
\text { Action Evaluation } \\
\text { (SPACE) Matrix }\end{array}$ & $\begin{array}{c}\text { Stage 2: The matching stage } \\
\text { Boston Consulting Group (BCG) } \\
\text { Matrix }\end{array}$ & $\begin{array}{l}\text { Internal-External } \\
\text { (IE) Matrix }\end{array}$ & Grand Strategy Matrix \\
\hline & & $\begin{array}{c}\text { Stage 3: The decision stage } \\
\text { Quantitative Strategic Planning } \\
\text { Matrix (QSPM) }\end{array}$ & & \\
\hline
\end{tabular}

Fig. 1. The Strategy-Formulation Analytical Framework

Formation of a CPM matrix is completed in three steps. In the first stage, CSFs for the industry are extracted and weighted. Next, the chief rivals are identified and scored for every factor. The last step involves application of factors coefficients to the scores of companies and obtaining the total score (rating) of the matrix. Multiplication and summation of both the CPM and EFE matrices yield the same results (Zimmerer et al., 2008). However, the basic success factors in CPM refer to internal and external issues and thus the ratings reflect strengths and weaknesses (David, 2011).

\subsection{Fuzzy DEMATEL}

The DEMATEL method is an expanded method for formation and analysis of a structural model based on casual relationships among important components (Wu \& Lee, 2007). This method has 
several attributes, one of which is presenting an efficient process for identifying hierarchies and relationships among system factors (Thakkar et al, 2006). The problem with the DEMATEL method is the certainty of values and the assumed conditions. Therefore, the fuzzy DEMATEL method was introduced for making decisions in uncertain conditions. In this method, variables of the fuzzy language are used to simplify decision making in uncertain conditions (Quan et al., 2011).

The use of the fuzzy DEMATEL method has increased recently and it has been used to perform analyses in various fields. One of the usages of this method is in identifying the major factors and criteria. Table 1 shows some of the examples of application of the fuzzy DEMATEL method to the identification of major components.

\section{Table 1}

Application of Fuzzy DEMATEL in Critical Success Factors analysis

\begin{tabular}{lll}
\hline Author(s) & Year & Type of Application \\
\hline Jassbi et al. & 2011 & Modeling cause and effect relationships of strategy map \\
Zhou et al. & 2011 & Identifying critical success factors in emergency management \\
Chang et al. & 2011 & Developing supplier selection criteria \\
Chou et al. & 2012 & Evaluating the criteria for human resource for science and technology \\
Wu & 2012 & Segmenting critical factors for successful knowledge management implementation \\
Patil \& Kant & 2014 & Predict success of knowledge management adoption in supply chain \\
\hline
\end{tabular}

The fuzzy DEMATEL method is applied as follows:

Step 1) We can turn the ambiguous judgments into triangular fuzzy numbers according to Table 2. This table shows fuzzy numbers in five class (Quan et al., 2011).

Table 2

Corresponding relationship between language and fuzzy number

\begin{tabular}{ll}
\hline Linguistic judgments & Corresponding triangular fuzzy number \\
\hline No influence & $(0,0,0.25)$ \\
Very low influence & $(0,0.25,0.5)$ \\
Low influence & $(0.25,0.5,0.75)$ \\
High influence & $(0.5,0.75,1)$ \\
Very high influence & $(0.75,1,1)$ \\
\hline
\end{tabular}

Step 2) Fuzzy matrix $\tilde{Z}$ (initial direct-relation fuzzy matrix) is produced which is shown as

$\tilde{Z}=\left[\begin{array}{cccc}0 & \tilde{z}_{12} & \cdots & \tilde{z}_{1 n} \\ \tilde{z}_{21} & 0 & \cdots & \tilde{z}_{2 n} \\ \vdots & \vdots & \ddots & \vdots \\ \tilde{z}_{n 1} & \tilde{z}_{n 2} & \cdots & 0\end{array}\right]$

where $\tilde{z}_{i j}=\left(l_{i j}, m_{i j}, u_{i j}\right)$ shows triangular fuzzy number in this matrix (Jassbi et al., 2011).

Step 3) We acquire normalized direct-relation fuzzy matrix $\tilde{X}$ by normalizing initial direct-relation fuzzy matrix, which is shown as

$\tilde{X}=\left[\begin{array}{cccc}0 & \tilde{x}_{12} & \cdots & \tilde{x}_{1 n} \\ \tilde{x}_{21} & 0 & \cdots & \tilde{x}_{2 n} \\ \vdots & \vdots & \ddots & \vdots \\ \tilde{x}_{n 1} & \tilde{x}_{n 2} & \cdots & 0\end{array}\right]$

where $\tilde{x}_{i j}=\frac{\tilde{z}_{i j}}{\tilde{R}}=\left(\frac{\tilde{z}_{i j, l}}{r_{l}}, \frac{\tilde{z}_{i j, m}}{r_{m}}, \frac{\tilde{z}_{i j, u}}{r_{u}}\right)$ and 
$r_{s}=\max _{1 \leq i \leq n}\left(\sum_{j=1}^{n} \tilde{z}_{i j, s}\right),(s=l, m, u)$ (Baykasoğlu et al, 2013).

Step 4) Now, the total-relation fuzzy matrix $\widetilde{T}$ is computed. This matrix is defined as

$\tilde{T}=\lim _{n \rightarrow \infty}\left(\tilde{X}+\tilde{X}^{2}+\cdots+\tilde{X}^{w}\right)=\tilde{X}(1-\tilde{X})^{-1}$.

Therefore, $\widetilde{T}$ matrix could be represented as follows,

$\tilde{T}=\left[\begin{array}{cccc}\tilde{t}_{11} & \tilde{t}_{12} & \cdots & \tilde{t}_{1 n} \\ \tilde{t}_{21} & \tilde{t}_{22} & \cdots & \tilde{t}_{2 n} \\ \vdots & \vdots & \ddots & \vdots \\ \tilde{t}_{n 1} & \tilde{t}_{n 2} & \cdots & \tilde{t}_{n n}\end{array}\right]$

where $\tilde{t}_{i j}=\left(t_{i j, l}, t_{i j, m}, t_{i j, u}\right)$ is the overall influence rating of decision maker for each criterion $i$ against criterion $j$.

Step 4) The sum of rows and sum of columns of the sub-matrices $t_{l}, t_{m}, t_{u}$ denoted by the fuzzy numbers $\widetilde{D}_{i}$ and $\widetilde{R}_{i}$, respectively, can be obtained through

$\widetilde{D}_{j}=\sum_{i=1}^{n} \tilde{t}_{i j}$

and

$\tilde{R}_{i}=\sum_{j=1}^{n} \tilde{t}_{i j}$ (Dalalah et al, 2011).

Step 5) To finalize the procedure, $\widetilde{D}_{i}$ and $\widetilde{R}_{i}$ are defuzzified through suitable defuzzification method. Then, there would be two sets of numbers: $\widetilde{D}_{i}{ }^{\text {def }}+\widetilde{R}_{i}{ }^{\text {def }}$ which shows how important the strategic objectives are, and $\widetilde{D}_{i}^{\text {def }}-\widetilde{R}_{i}^{\text {def }}$ which shows which strategic objective is cause and which one is effect (Baykasoğlu et al., 2013).

\section{Conceptual Model}

The model used in this research was a combination of the Competitive Profile Matrix (CPM) and the fuzzy DEMATEL method. Using the aforementioned method, the required weights are obtained from the CPM and then the weights are applied as coefficients of all options (rival companies) to obtain the numerical rating results. It is worth mentioning that using the output of the fuzzy DEMATEL method, major enhancement attributes are determined and the path to the enhancement of the performance of the company in the competitive market is shown. Fig. 2 shows the model proposed in this research.

The importance of the criteria is calculated with the following equation:

$\omega_{i}=\left\{\left(\widetilde{D}_{i}^{d e f}+\tilde{R}_{i}^{d e f}\right)^{2}+\left(\widetilde{D}_{i}^{d e f}-\widetilde{R}_{i}^{d e f}\right)^{2}\right\}^{\frac{1}{2}}$.

The importance of any criterion can be normalized as follows: 
$W_{i}=\frac{\omega_{i}}{\sum_{i=1}^{n} \omega_{i}}$

where $W_{i}$ represents the final criteria weights to be used in the decision making process (Dalalah et al,2011).

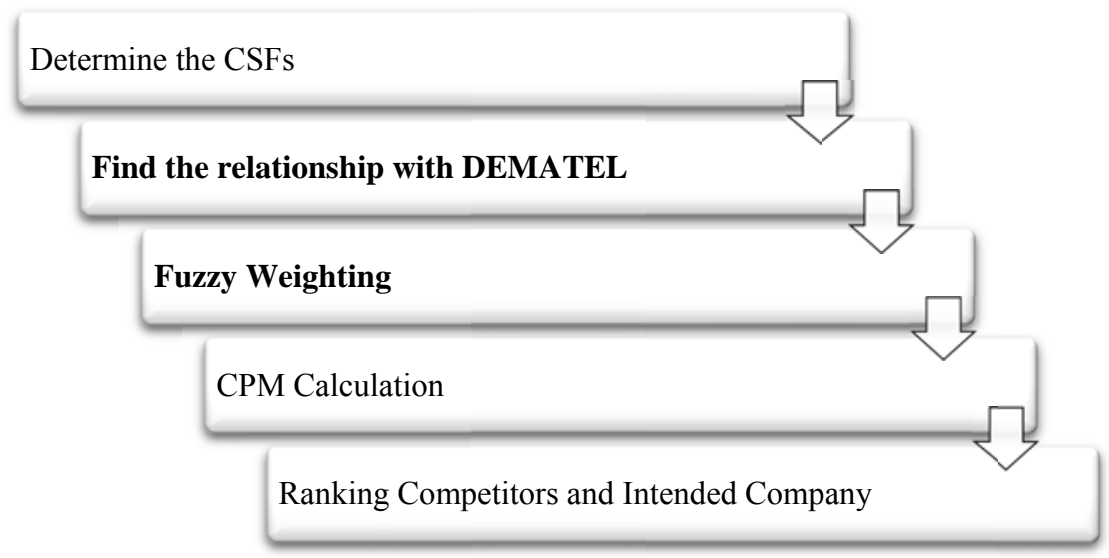

Fig. 2. Conceptual Model

\section{Numerical example}

A sample Competitive Profile Matrix is provided in Table 3 (David, 2011).

Table 3

An example Competitive Profile Matrix with Fuzzy Weighting

\begin{tabular}{lcccccc}
\hline & \multicolumn{2}{c}{ Company 1} & \multicolumn{2}{c}{ Company 2} & \multicolumn{2}{c}{ Company 3} \\
\hline Critical Success Factors & Rating & Score & Rating & Score & Rating & Score \\
\hline Advertising & 1 & $W_{i} \cdot R_{i j}$ & 4 & $W_{i} \cdot R_{i j}$ & 3 & $W_{i} \cdot R_{i j}$ \\
Product Quality & 4 & $W_{i} \cdot R_{i j}$ & 3 & $W_{i} \cdot R_{i j}$ & 2 & $W_{i} \cdot R_{i j}$ \\
Price Competitiveness & 3 & $W_{i} \cdot R_{i j}$ & 2 & $W_{i} \cdot R_{i j}$ & 4 & $W_{i} \cdot R_{i j}$ \\
Management & 4 & $W_{i} \cdot R_{i j}$ & 3 & $W_{i} \cdot R_{i j}$ & 3 & $W_{i} \cdot R_{i j}$ \\
Financial Position & 4 & $W_{i} \cdot R_{i j}$ & 2 & $W_{i} \cdot R_{i j}$ & 3 & $W_{i} \cdot R_{i j}$ \\
Customer Loyalty & 4 & $W_{i} \cdot R_{i j}$ & 3 & $W_{i} \cdot R_{i j}$ & 2 & $W_{i} \cdot R_{i j}$ \\
Global Expansion & 4 & $W_{i} \cdot R_{i j}$ & 1 & $W_{i} \cdot R_{i j}$ & 2 & $W_{i} \cdot R_{i j}$ \\
Market Share & 1 & $W_{i} \cdot R_{i j}$ & 4 & $W_{i} \cdot R_{i j}$ & 3 & $W_{i} \cdot R_{i j}$ \\
\hline Total & & & & & & \\
\hline
\end{tabular}

In this matrix, the weights of CSFs calculated with DEMATEL method. This calculation is represented as below:

\section{Table 4}

The assessment data fuzzy matrix of a general manager

\begin{tabular}{|c|c|c|c|c|c|c|c|c|}
\hline & Advertising & Product Quality & Price Competitiveness & Management & $\begin{array}{c}\text { Financial } \\
\text { Position }\end{array}$ & $\begin{array}{c}\text { Customer } \\
\text { Loyalty }\end{array}$ & $\begin{array}{c}\text { Global } \\
\text { Expansion }\end{array}$ & $\begin{array}{c}\text { Market } \\
\text { Share }\end{array}$ \\
\hline Advertising & 0 & No & $\mathrm{L}$ & $\mathrm{L}$ & $\mathrm{H}$ & $\mathrm{H}$ & $\mathrm{VH}$ & $\mathrm{H}$ \\
\hline Product Quality & VL & 0 & $\mathrm{H}$ & $\mathrm{H}$ & $\mathrm{L}$ & $\mathrm{VH}$ & $\mathrm{H}$ & $\mathrm{H}$ \\
\hline Price Competitiveness & $\mathrm{L}$ & $\mathrm{H}$ & 0 & $\mathrm{H}$ & $\mathrm{H}$ & $\mathrm{L}$ & $\mathrm{VL}$ & $\mathrm{H}$ \\
\hline Management & VL & $\mathrm{L}$ & VL & 0 & $\mathrm{~L}$ & VL & $\mathrm{L}$ & $\mathrm{L}$ \\
\hline Financial Position & $\mathrm{L}$ & No & $\mathrm{H}$ & $\mathrm{H}$ & 0 & No & $\mathrm{H}$ & $\mathrm{L}$ \\
\hline Customer Loyalty & VL & $\mathrm{H}$ & $\mathrm{L}$ & $\mathrm{L}$ & $\mathrm{L}$ & 0 & $\mathrm{H}$ & $\mathrm{H}$ \\
\hline Global Expansion & $\mathrm{L}$ & $\mathrm{L}$ & $\mathrm{H}$ & $\mathrm{L}$ & $\mathrm{H}$ & $\mathrm{VL}$ & 0 & $\mathrm{H}$ \\
\hline Market Share & $\mathrm{H}$ & VL & $\mathrm{H}$ & VL & $\mathrm{VH}$ & $\mathrm{L}$ & VL & 0 \\
\hline
\end{tabular}

After calculation of matrix $\tilde{Z}$ and matrix $\tilde{X}$, the total-relation fuzzy matrix $\tilde{T}$ is computed from $\tilde{X}(1-\tilde{X})^{-1}$ as follows 


\begin{tabular}{|c|c|c|c|c|c|c|c|c|}
\hline & & & & & & & & \\
\hline & 0.215 & 0.202 & 0.432 & 0.373 & 0.569 & 0.333 & 0.519 & 0.528 \\
\hline & 0.218 & 0.236 & 0.516 & 0.471 & 0.517 & 0.435 & 0.458 & 0.559 \\
\hline & 0.258 & 0.324 & 0.313 & 0.427 & 0.517 & 0.274 & 0.286 & 0.488 \\
\hline$\tilde{T}_{l}=$ & 0.085 & 0.148 & 0.147 & 0.119 & 0.239 & 0.082 & 0.193 & 0.222 \\
\hline & 0.228 & 0.147 & 0.389 & 0.366 & 0.303 & 0.136 & 0.352 & 0.348 \\
\hline & 0.180 & 0.322 & 0.384 & 0.336 & 0.432 & 0.182 & 0.396 & 0.475 \\
\hline & 0.260 & 0.236 & 0.445 & 0.338 & 0.504 & 0.178 & 0.246 & 0.464 \\
\hline & 0.317 & 0.151 & 0.420 & 0.253 & 0.543 & 0.234 & 0.255 & 0.296 \\
\hline & 0.398 & 0.346 & 0.616 & 0.596 & 0.722 & 0.498 & 0.673 & 0.696 \\
\hline & 0.491 & 0.396 & 0.721 & 0.707 & 0.747 & 0.602 & 0.690 & 0.769 \\
\hline & 0.490 & 0.480 & 0.524 & 0.652 & 0.722 & 0.476 & 0.554 & 0.701 \\
\hline$n$ & 0.319 & 0.324 & 0.408 & 0.342 & 0.491 & 0.305 & 0.432 & 0.475 \\
\hline & 0.404 & 0.268 & 0.537 & 0.532 & 0.455 & 0.287 & 0.515 & 0.527 \\
\hline & 0.434 & 0.474 & 0.605 & 0.587 & 0.661 & 0.367 & 0.616 & 0.683 \\
\hline & 0.476 & 0.417 & 0.639 & 0.583 & 0.699 & 0.409 & 0.471 & 0.674 \\
\hline & 0.497 & 0.350 & 0.609 & 0.512 & 0.707 & 0.428 & 0.504 & 0.505 \\
\hline & 0.757 & 0.741 & 1.023 & 0.979 & 1.092 & 0.857 & 1.000 & 1.109 \\
\hline & 0.894 & 0.765 & 1.132 & 1.088 & 1.140 & 0.923 & 1.072 & 1.193 \\
\hline & 0.893 & 0.866 & 0.953 & 1.051 & 1.128 & 0.861 & 0.974 & 1.149 \\
\hline$\tilde{T}_{u}$ & 0.685 & 0.671 & 0.816 & 0.707 & 0.876 & 0.658 & 0.804 & 0.891 \\
\hline & 0.773 & 0.656 & 0.941 & 0.907 & 0.839 & 0.674 & 0.892 & 0.959 \\
\hline & 0.840 & 0.850 & 1.037 & 0.993 & 1.071 & 0.733 & 1.011 & 1.123 \\
\hline & 0.869 & 0.808 & 1.061 & 0.988 & 1.098 & 0.802 & 0.865 & 1.115 \\
\hline & 0.844 & 0.724 & 0.992 & 0.892 & 1.027 & 0.781 & 0.879 & 0.905 \\
\hline
\end{tabular}

The result of $\widetilde{D}_{i}$ and $\widetilde{R}_{i}$ is:

\begin{tabular}{llcc}
\hline & Critical Success Factors & $\widetilde{D}_{i}$ & $\widetilde{R}_{i}$ \\
\hline C1 & Advertising & $(1.761,3.509,14.358)$ & $(4.355,5.236,-3.630)$ \\
C2 & Product Quality & $(1.766,3.056,15.521)$ & $(-3.121,-4.109,6.653)$ \\
C3 & Price Competitiveness & $(3.047,4.658,14.856)$ & $(-0.137,-0.503,-1.115)$ \\
C4 & Management & $(2.682,4.511,11.529)$ & $(-10.461,-2.001,-0.901)$ \\
C5 & Financial Position & $(3.622,5.204,12.509)$ & $(-1.866,0.893,-4.187)$ \\
C6 & Customer Loyalty & $(1.854,3.373,14.474)$ & $(4.227,-1.397,3.979)$ \\
C7 & Global Expansion & $(2.704,4.455,14.344)$ & $(1.611,2.811,-0.041)$ \\
C8 & Market Share & $(3.381,5.031,13.244)$ & $(0.346,-0.930,-0.758)$ \\
\hline
\end{tabular}

then, by calculation of $\left(\widetilde{D}_{i}\right)^{\text {def }}$ and $\left(\widetilde{R}_{i}\right)^{\text {def }}, \widetilde{D}_{i}^{\text {def }}+\widetilde{R}_{i}^{\text {def }}$ and $\widetilde{D}_{i}^{\text {def }}-\widetilde{R}_{i}^{\text {def }}$ is computed as

\begin{tabular}{llcc}
\hline & Critical Success Factors & $\widetilde{D}_{i}^{\text {def }}+\widetilde{R}_{i}^{\text {def }}$ & $\widetilde{D}_{i}^{\text {def }}-\widetilde{R}_{i}^{\text {def }}$ \\
\hline C1 & Advertising & 9.844345 & 0.207093 \\
C2 & Product Quality & 10.26901 & -0.43255 \\
C3 & Price Competitiveness & 10.94834 & 1.230322 \\
C4 & Management & 8.663554 & 2.088001 \\
C5 & Financial Position & 9.992951 & 2.322147 \\
C6 & Customer Loyalty & 9.648872 & 0.291277 \\
C7 & Global Expansion & 10.43627 & 1.186381 \\
C8 & Market Share & 10.45168 & 1.797342 \\
\hline
\end{tabular}




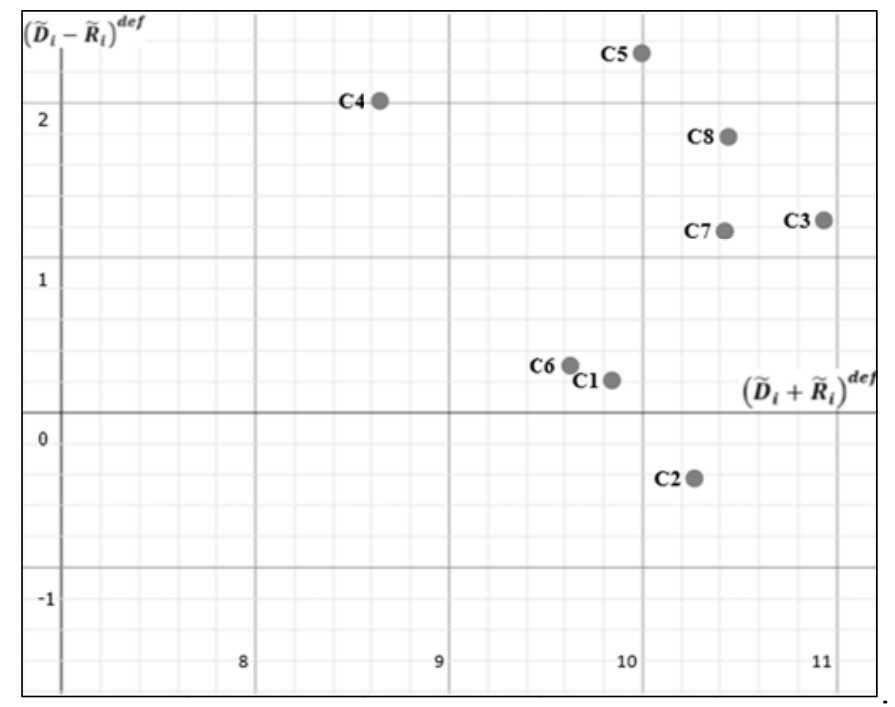

Fig. 3. The cause-effect relationship diagram

Therefore, the weights of Critical Success Factors are computed:

\begin{tabular}{llcc}
\hline & Critical Success Factors & $\omega_{i}$ & $W_{i}$ \\
\hline C1 & Advertising & 9.846523 & 0.12145 \\
C2 & Product Quality & 10.27811 & 0.126774 \\
C3 & Price Competitiveness & 11.01726 & 0.13589 \\
C4 & Management & 8.911617 & 0.109919 \\
C5 & Financial Position & 10.25921 & 0.12654 \\
C6 & Customer Loyalty & 9.653267 & 0.119067 \\
C7 & Global Expansion & 10.50349 & 0.129553 \\
C8 & Market Share & 10.60509 & 0.130807 \\
\hline
\end{tabular}

and the values of $W_{i}$ are used as weights required by the CPM.

\section{Conclusion}

In sum, it can be said that application of the fuzzy logic to the strategic formulation process leads to realistic results. In the model presented in this paper, the fuzzy DEMATEL method along with competitive profile matrix (CPM) was used to take another step toward the reality of the market under study. Because of this attempt, the process of strategic planning is more reliable in uncertain conditions and yields better results.

\section{Future Studies}

The following recommendations are provided to extend this research:

1. Using fuzzy ratings in the CPM in order to obtained more precise results in uncertain conditions

2. Using the multiple attribute decision making method (MADM) to obtained more satisfactory ratings

The above solutions can be used to develop and extend the present research.

\section{References}

Baykasoğlu, A., Kaplanoğlu, V., Durmuşoğlu, Z. D.U., \& Şahin, C. (2013). Integrating fuzzy DEMATEL and fuzzy hierarchical TOPSIS methods for truck selection. Expert Systems with Applications, 40(3), 899-907 
Dalalah, D., Hayajneh, M., \& Batieha, F. (2011). A fuzzy multi-criteria decision making model for supplier selection. Expert Systems with Applications, 38(7), 8384-8391.

David, F. (2011). Strategic management; concepts and cases (13th edition). Prentice Hall.

Huang, H.C. (2009). designing a knowledge-based system for strategic planning: A balanced scorecard perspective. Expert Systems with Applications, 36(1), 209-218.

Jassbi, J., Mohamadnejad, F., \& Nasrollahzadeh, H. (2011). A Fuzzy DEMATEL framework for modeling cause and effect relationships of strategy map. Expert Systems with Applications, 38, 5967-5973.

Moradi, F. (2011). A Comprehensive Look at Strategic Management. (Farsi Book). Tehran: Industrial Management Institute. ISBN: 978-964-8896-85-5.

Quan, Z., HuangWeila. I., \& Zhang, Y. (2011). Identifying critical success factors in emergency management using a fuzzy DEMATEL method. Safety Science, 49(2), 243-252

Ramachandran, K., \& Voleti, S. (2004). Business process outsourcing (BPO): emerging scenario and strategic options for IT-enabled services. Vikaipa, 29(1), 49-62.

Thakkar, J., Deshmukh, S.G., Gupta, A.D., \& Shankar, R., (2006). Development of a balanced scorecard: An integrated approach of interpretive structural modeling (ISM) and analytic network process (ANP). International Journal of Productivity and Performance Management, 56(1), 2559.

Wu, W.W., \& Lee, Y.T. (2007). Developing global managers' competencies using the fuzzy DEMATEL method. Expert System with Applications, 32(2), 499-507.

Zimmerer, T., Scarborough, N. M., \& Wilson, D. (2008). Essentials of entrepreneurship and small business management (5th ed.). Upper Saddle River, NJ: Prentice Hall. 